$11-25-2008$

\title{
Hemispheric Differences in the Recognition of Environmental Sounds
}

Julio Gonza'lez

Universitat Jaume I de Castellon

Conor T. McLennan

Cleveland State University, c.mclennan@csuohio.edu

Follow this and additional works at: https://engagedscholarship.csuohio.edu/clpsych_facpub

Part of the Speech and Hearing Science Commons

How does access to this work benefit you? Let us know!

Publisher's Statement

(c) 2009 SAGE Publications

\section{Recommended Citation}

González, J., \& McLennan, C. T. (2009). Hemispheric differences in the recognition of environmental sounds. Psychological Science, 20(7), 887-894. doi:10.1111/psci.2009.20.issue-7

This Article is brought to you for free and open access by the Psychology Department at EngagedScholarship@CSU. It has been accepted for inclusion in Psychology Faculty Publications by an authorized administrator of EngagedScholarship@CSU. For more information, please contact library.es@csuohio.edu. 


\title{
Hemispheric Differences in the Recognition of Environmental Sounds
}

\author{
Julio González ${ }^{1}$ and Conor T. M'Lennan $^{2}$ \\ ${ }^{1}$ University Jaume I and ${ }^{2}$ Cleveland State University
}

\begin{abstract}
Recent work has found support for two dis sociable and parallel neural subsystems underlying object and shape recognition in the visual domain: an abstract category subsystem that operates more effectively in the left cerebral hemisphere than in the right, and a specific exemplar subsystem that operates more effectively in the right hemisphere than in the left. Evidence of this asym metry has been observed for linguistic stimuli (words, pseudoword forms) and nonlinguistic stimuli (objects). In the auditory domain, we previously found hemispheric asymmetries in priming effects using linguistic stimuli (spoken words). In the present study, we conducted four long term repetition priming experiments to investigate whether such hemispheric asymmetries would be observed for nonlinguistic auditory stimuli (environmental sounds) as well. The results support the dissociable subsystems theory. Specificity effects were obtained when sounds were presented to the left ear (right hemisphere), but not when sounds were presented to the right ear (left hemisphere). Theoretical implications are discussed.
\end{abstract}

There is an ongoing debate concerning the nature of the repre sentations involved in object recognition in the visual domain. Marsolek and his colleagues hypothesize the existence of two dissociable and parallel neural subsystems: The abstract cate gory subsystem operates more effectively in the left than in the right hemisphere and is less sensitive to specific surface char acteristics of stimuli, and the specific exemplar subsystem oper ates more effectively in the right than in the left hemisphere and is more sensitive to specific stimulus characteristics (Marsolek, 1999; Marsolek \& Burgund, 2008). This theory would explain the apparent dilemma of why two objects (e.g., two different exemplars of pianos) are recognized as belonging to the same abstract category, but also to different specific categories.

The dissociable subsystems framework challenges other contemporary object recognition theories proposing a single and undifferentiated object recognition system. These theories differ in whether this single system relies on relatively abstract representations (Biederman, 1987; Hayworth \& Biederman, 2006; Wagemans, Van Gool, \& Lamote, 1996), relatively specific representations (Bulthoff \& Edelman, 1992; Tarr, Williams, Hayward, \& Gauthier, 1998), or both abstract and specific representations on a continuum (Farah, 1992; Hayward \& Williams, 2000).

Behavioral evidence for two dissociable subsystems has been found in the recognition of objects, words, pseudoword forms, and letterlike forms (but see Koivisto, 1995; for a review, see Marsolek, 2003). Other data from neuropsychology (Beeri, Vakil, Adonsky, \& Levenkron, 2004; Farah, 1991), electrophysiology (Pickering \& Schweinberger, 2003), and functional magnetic resonance imaging (Koutstaal et al., 2001) are consistent with the dissociable subsystems account. Neurocomputational simula tions show that abstract and specific categorizations are per formed more effectively by a dual subsystems model than by a single system model, particularly when abstract categories in clude both similar and dissimilar exemplars (see Marsolek, 2003).

The strongest support for the dissociable subsystems theory comes from studies using the long term repetition priming par adigm. In this paradigm, priming (enhancement of performance) due to repetition of a stimulus may be attenuated if the first and second presentations of the stimulus mismatch on some di mension (e.g., different letter case for words or different exem plars for objects). This attenuation of priming is referred to as specificity. In a study of object recognition, Marsolek (1999) 
reported distinct patterns of specificity in the two hemispheres. Participants named objects (e.g., a piano) presented in either the left visual field (right hemisphere) or the right visual field (left hemisphere) after having viewed a series of centrally presented objects during an initial encoding phase. Some of the test objects were repetitions of the same exemplars seen during encoding, and others had been preceded by different exemplars from the same category (e.g., one exemplar of a piano during encoding and a different exemplar of a piano during test). Equivalent priming was obtained in the same and different exemplar conditions when test objects were presented to the left hemi sphere, but priming was reduced in the different exemplar condition (a demonstration of specificity) when test objects were presented to the right hemisphere. A similar pattern of right hemisphere specificity was obtained when objects did or did not vary in depth orientation (Burgund \& Marsolek, 2000) and when the objects used were unfamiliar or novel (Marsolek \& Burgund, 2008).

There are reasons to believe that two dissociable neural subsystems may underlie abstract and specific perception be yond the visual domain. We recently obtained hemispheric differences in talker specificity effects in spoken word recog nition (González \& McLennan, 2007), a finding analogous to Marsolek and his colleagues' findings of hemispheric differ ences in letter case specificity effects in visual word recognition (Burgund \& Marsolek, 1997; Marsolek, 2004). Specifically, we observed that the right hemisphere was more sensitive than the left hemisphere to surface information associated with talker identity. The question of interest in the study we report here is whether this hemispheric asymmetry in auditory priming is unique to linguistic stimuli, or whether it extends to nonlin guistic stimuli. If the asymmetry does extend to nonlinguistic stimuli, then it can be considered a general property of the au ditory perceptual system, and we should obtain the same pattern of results in the auditory recognition of environmental sounds as in the auditory recognition of linguistic sounds.

Dichotic listening, neuropsychological, electrophysiological, and neuroimaging studies have provided a great deal of evi dence for auditory processing asymmetries (see Tervaniemi \& Hugdahl, 2003), and demonstrate that such asymmetries are not limited to a single domain (e.g., language, music, environmental sounds). However, no hemispheric distinction can account for all the data (Sanders \& Poeppel, 2007). In particular, classical dichotic listening studies revealed an overall right ear advan tage for processing some types of verbal stimuli and a left ear advantage for processing prosody, some aspects of music, and environmental sounds (Hugdahl, 1999); however, no study to date has investigated the lateralization of specificity effects.

In the present study, we tested hemispheric asymmetries in specificity by performing four long term repetition priming ex periments in which the task was to identify environmental sounds. An obvious prerequisite was demonstration that such stimuli are subject to long term priming and specificity effects in the first place. Some studies have reported priming for envi ronmental sounds (Chiu, 2000; Chiu \& Schacter, 1995; Stuart \& Jones, 1996), and one study obtained specificity effects (Chiu, 2000). In particular, Chiu observed exemplar specificity effects in four repetition priming experiments in which participants attempted to identify environmental sounds from their initial sound stems or to identify environmental sounds embedded in white noise. He found that priming was more robust when a sound was repeated than when it was preceded by a different exemplar from the same category. Our aim was to investigate potential hemispheric differences in exemplar specificity effects during the recognition of environmental sounds. We expected to find a pattern similar to that reported by Marsolek (1999) in his work on visual object recognition. In particular, we predicted significantly better performance in sound recognition after same exemplar priming than after different exemplar priming when stimuli were presented to the right hemisphere, but not when they were presented to the left hemisphere.

In each experiment, 24 (Experiments 1 and 2) or 30 (Exper iments 3 and 4) participants of both sexes, recruited from the University Jaume I, volunteered in return for course credit. All participants were right handed (Edinburgh Handedness In ventory; Oldfield, 1971) native speakers of Spanish with no re ported history of speech or hearing disorders. No one participated in more than one experiment.

\section{EXPERIMENT 1}

\section{Method}

\section{Materials}

The experimental stimuli consisted of 24 digitized target sounds (see Table 1) that were selected from Marcell, Borella, Greene, Kerr, and Rogers's (2000) database as representing a variety of everyday nonverbal acoustic events, such as sounds produced by animals, people, musical instruments, tools, and other ob jects. According to the normative data reported by Marcell et al., the mean naming accuracy for these sounds was 78\%. Following Shafiro and Gygi's (2004) guidelines, we selected an additional

\section{TABLE 1}

Target Stimuli Used in the Experiments

Experiments 1 2: bagpipes, boat horn, chewing, child coughing, church bells, coin dropping, cutting paper, drill, elephant, frying food, gong, harmonica, helicopter, jackhammer, monkey, ocean, owl, pouring water, thunder, toilet flushing, turning pages, violin, wind, yawning

Experiments 3 4: accordion, airplane, brushing teeth, cash register, clapping, crumpling paper, donkey, dropping ice in a glass, flute, gargling, guitar, harp, horse galloping, lion, organ, ping pong, police siren, rattlesnake, snoring, train, typewriter, whistling, wolf, zipper

Note. These stimuli were obtained from Marcell, Borella, Greene, Kerr, and Rogers (2000). 
set of 24 digitized sounds from a variety of sound databases. These sounds represented the same acoustic events as the target set. Thus, we had two exemplars for each event. Both sets of sounds were 16 bit WAV files saved at a sampling rate of 22,050 $\mathrm{Hz}$. Durations of the sound files ranged from 1.1 to $5.9 \mathrm{~s}$. A different set of environmental sounds was used as filler stimuli. All audio files were equated in root mean square (RMS) amplitude. Auditory stems were created by digitally truncating each target sound so that only the initial $750 \mathrm{~ms}$ were preserved (Chiu, 2000, and Chiu \& Schacter, 1995, used the first $1,000 \mathrm{~ms}$ ).

\section{Design and Procedure}

The design was similar to that of other long term repetition priming experiments (González \& McLennan, 2007; McLennan \& Luce, 2005; McLennan, Luce, \& Charles Luce, 2003). Par ticipants were seated in front of a computer and listened to stimuli presented in two blocks. In the first block (the study phase), 24 stimuli were presented binaurally in random order (8 same exemplar primes, 8 different exemplar primes, and 8 fillers). These stimuli were preceded and followed by 2 addi tional fillers to minimize primacy and recency effects (Chiu, 2000). Participants were instructed to type the name of the acoustic event represented by the sound in each trial. After a short distractor task (performing arithmetic operations for 45 min), participants received the second block (the test phase). During this block, they were instructed to identify target sounds from their $750 \mathrm{~ms}$ sound stems. Stems were presented monau rally in random order. Half the stems were presented to the left ear, and half were presented to the right ear. Note that because the majority of neural projections are contralateral, a stimulus presented to the right ear should be processed more efficiently in the left than in the right hemisphere, and a stimulus presented to the left ear should be processed more efficiently in the right than in the left hemisphere. Of the 24 sound stems presented in the test phase, 8 were primed by a same exemplar sound in the study phase, 8 were primed by a different exemplar sound in the study phase, and 8 were unprimed (the control condition).

The experiment was conducted on a Pentium PC computer, using Inquisit 1.33 software, and stimuli were presented over calibrated headphones (AKG K55; Vienna, Austria) at $70 \mathrm{~dB}$ in a quiet room. Examples of possible correct responses were given during three preliminary practice trials, but not during the study or test phases.

The experimental design was an orthogonal combination of three levels of prime type (same exemplar, different exemplar, and control) and two levels of ear of target stem presentation (left and right). Table 2 summarizes the six within participants conditions. Six stimulus lists were created to ensure that each target stem was assigned to every possible condition across participants. No participant heard more than one version of a given sound within a block.
TABLE 2

Experimental Conditions in the Four Experiments

\begin{tabular}{lcc}
\hline \hline Condition & Block 1: prime & Block 2: target \\
\hline Same exemplar & bagpipe & bagpipe $_{\mathrm{A}}$ \\
Different exemplar & bagpipe & bagpipe $_{\mathrm{A}}$ \\
Control & duck & bagpipe $_{\mathrm{A}}$ \\
\hline
\end{tabular}

Note. The conditions are illustrated by examples of stimuli used in Experiments 1 and 2. Subscripts identify different exemplars of the same sound event. Complete sound files were presented binaurally during Block 1, and truncated versions (target stems) were presented monaurally in Block 2 . The target stems were presented to the right ear on half the trials and to the left ear on the other half.

\section{Results}

Responses in the test phase were scored according to the guidelines for scoring naming responses outlined by Marcell et al. (2000, pp. 836 842). Figure 1 displays the mean proportion of naming accuracy as a function of prime type and ear of target stem presentation. Separate analyses were carried out with par ticipants $\left(F_{1}, t_{1}\right)$ and items $\left(F_{2}, t_{2}\right)$ as the random variable.

Accuracy was analyzed in a two way repeated measures analysis of variance (ANOVA) with prime type (same exemplar, different exemplar, or unprimed control) and ear of target stem presentation (left or right) as within participants factors. Planned comparisons were performed to examine any possible difference between the same exemplar and different exemplar conditions for each ear (hemisphere). We observed a significant main effect of prime type, $F_{1}(2,46)=10.20, M S E=0.038$,

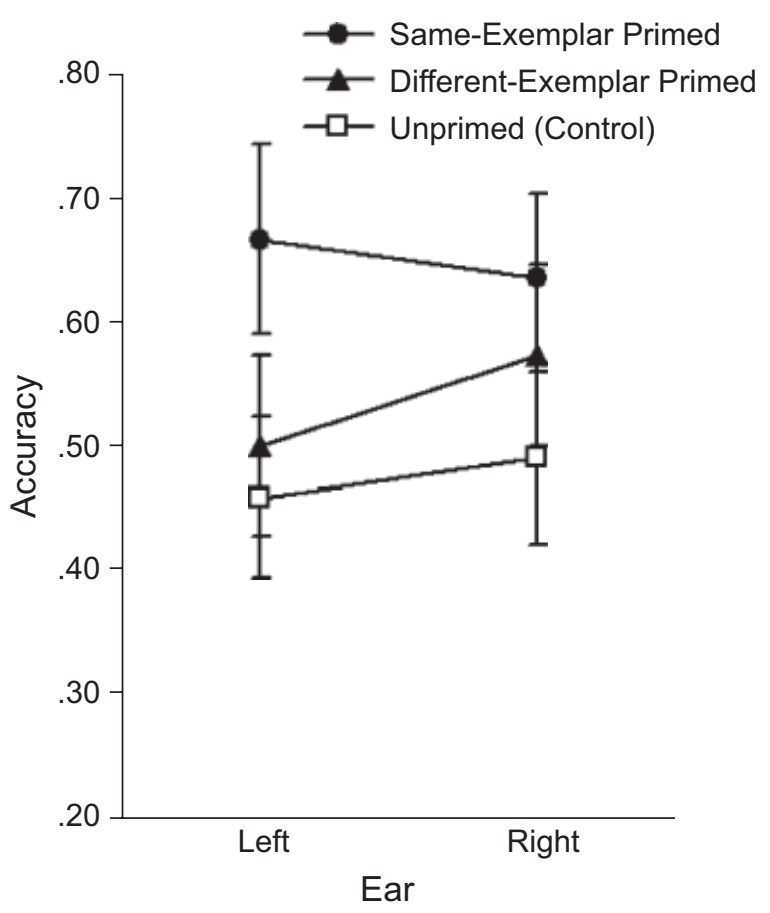

Fig. 1. Mean proportion of naming accuracy in Experiment 1 as a function of prime type and ear of target-stem presentation. Error bars indicate standard errors of the means. 
$\eta_{p}{ }^{2}=.31 ; F_{2}(2,46)=10.20, M S E=0.038, \eta_{p}{ }^{2}=.31$. No other significant effect was obtained. Post hoc analyses revealed significant differences between the same exemplar and control conditions, and between the same exemplar and different exemplar conditions.

Crucially, planned comparisons demonstrated that the differ ence between the same exemplar and different exemplar con ditions ( $M \mathrm{~s}=.64$ and .57 , respectively) was not significant when the target stems were presented to the right ear (both $t \mathrm{~s}<1$ ), but was significant $(M \mathrm{~s}=.67$ and .50$)$ when the target stems were presented to the left ear, $t_{1}(23)=3.56, p<.003, p_{\text {rep }}=.99$, $d=0.73 ; t_{2}(23)=3.56, p<.003, p_{\text {rep }}=.99, d=0.73$.

\section{Discussion}

These results are consistent with our predictions based on Marsolek's $(1999,2003)$ results in the visual domain. In par ticular, exemplar specificity effects emerged when the target stimuli were presented to the left ear (right hemisphere), but not when the target stimuli were presented to the right ear (left hemisphere).

\section{EXPERIMENT 2}

In an attempt to minimize the involvement of the hemisphere on the same side as the ear receiving the target stimuli (via ipsi lateral projections), in Experiment 2 we presented noise to the ear not receiving each auditory target stem. Presenting infor mation to the two hemispheres simultaneously would be ex pected to increase competition between the hemispheres and to increase the likelihood of observing hemispheric asymmetries (Fecteau, Enns, \& Kingstone, 2000; González \& McLennan, 2007; Kimura, 1961).

\section{Method}

The materials, design, and procedure were all identical to those of Experiment 1, with the following exceptions: A $750 \mathrm{~ms}$ audio file containing white noise was created; the noise was low pass filtered at $11,025 \mathrm{~Hz}$ and digitized at a sampling rate of 22,050 $\mathrm{Hz}$, and the RMS amplitude was set to $5 \mathrm{~dB}$ below the level of the sound files. During each trial in the test phase, a sound stem was presented in one ear, and the noise was presented simulta neously in the opposite ear.

\section{Results}

Figure 2 displays the mean proportion of naming accuracy as a function of prime type and ear of target stem presentation. As expected, overall performance was lower than in Experiment 1 because of the noise's masking effect. We observed a significant main effect of prime type, $F_{1}(2,46)=25.87, M S E=0.052$, $\eta_{p}{ }^{2}=.53 ; F_{2}(2,46)=19.67, M S E=0.068, \eta_{p}{ }^{2}=.46$. Post hoc analyses revealed significant differences among the three priming conditions.

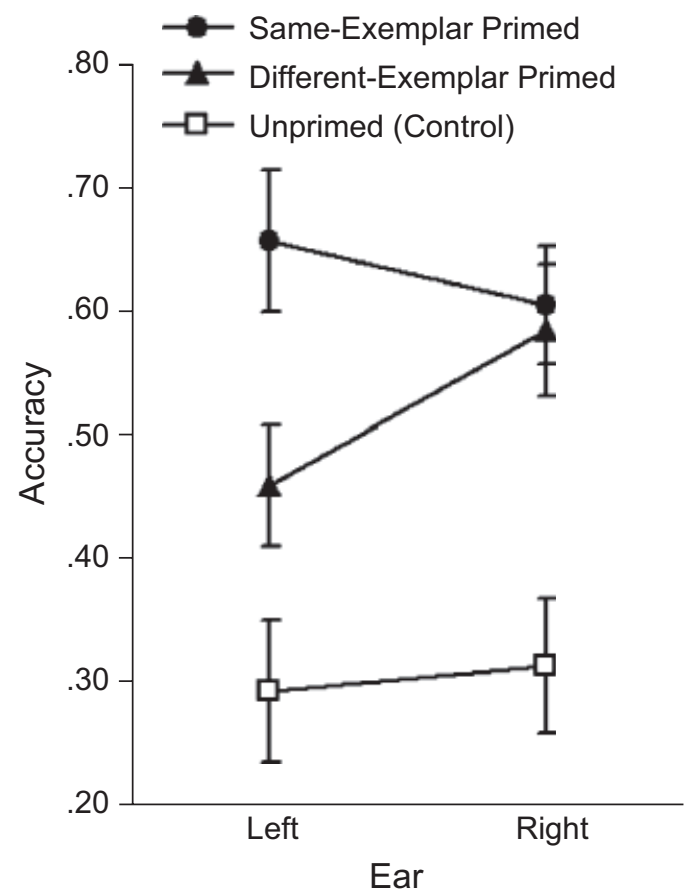

Fig. 2. Mean proportion of naming accuracy in Experiment 2 as a function of prime type and ear of target-stem presentation. Error bars indicate standard errors of the means.

Crucially, planned comparisons demonstrated that the difference between the same exemplar and different exemplar conditions ( $M \mathrm{~s}=.60$ and .58 , respectively) was not significant when the target stems were presented to the right ear (both $t \mathrm{~s}<$ $1)$, but was significant $(M \mathrm{~s}=.66$ and .46$)$ when the target stems were presented to the left ear, $t_{1}(23)=2.74, p<.02, p_{\text {rep }}=.91$, $d=0.56 ; t_{2}(23)=2.74, p<.02, p_{\text {rep }}=.91, d=0.56$.

\section{Discussion}

Once again, the results are consistent with our predictions based on Marsolek's $(1999,2003)$ results in the visual domain. In particular, exemplar specificity effects emerged when the target stimuli were presented to the left ear (right hemisphere), but not when the target stimuli were presented to the right ear (left hemisphere).

In order to test the generalizability of the pattern of results, we planned two additional experiments that used a new set of stimuli and a new task during the study phase (i.e., different study and test tasks). An advantage of using different tasks during the two phases was that this minimized the likelihood that simple, rapid stimulus response learning was responsible for any priming effects observed (Dobbins, Schnyer, Verfaellie, \& Schacter, 2004).

\section{EXPERIMENT 3}

\section{Method}

The method in Experiment 3 was identical to that in Experiment 1, with two exceptions. First, from the Marcell et al. (2000) 
database, we selected a new set of 24 digitized target sounds representing a new set of acoustic events (see Table 1). Ac cording to the normative data reported by Marcell et al., the mean naming accuracy for these sounds was $80 \%$. Following Shafiro and Gygi's (2004) guidelines, we selected from a variety of sound databases an additional set of 24 digitized sounds representing the same acoustic events as the target set. Dura tions of the sound files ranged from 1.2 to $5.9 \mathrm{~s}$. Second, during the study block, a pleasantness rating task was used. Partici pants were instructed to rate each sound for "pleasantness" on a scale from 1 (unpleasant) to 4 (pleasant). This task has been used in other long term priming experiments during the study phase (González \& McLennan, 2007; Schacter \& Church, 1992).

\section{Results}

Figure 3 displays the mean proportion of naming accuracy as a function of prime type and ear of target stem presentation. We observed a significant main effect of prime type, $F_{1}(2,58)=$ $6.20, M S E=0.041, \eta_{p}{ }^{2}=.18 ; F_{2}(2,46)=4.63, M S E=0.043$, $\eta_{p}{ }^{2}=.17$. No other significant effect was obtained. Post hoc analyses revealed significant differences between the same exemplar and control conditions, and between the same exem plar and different exemplar conditions.

Crucially, planned comparisons demonstrated that the differ ence between the same exemplar and different exemplar con ditions $(M \mathrm{~s}=.56$ and .52 , respectively) was not significant when the target stems were presented to the right ear (both $t \mathrm{~s}<1$ ), but was significant $(M \mathrm{~s}=.62$ and .48$)$ when the target stems were presented to the left ear, $t_{1}(29)=2.29, p<.04, p_{\text {rep }}=.88, d=$ $0.42 ; t_{2}(29)=2.43, p<.03, p_{\text {rep }}=.96, d=0.50$.

\section{Discussion}

Our data showed the same pattern as in the previous experi ments: Exemplar specificity emerged when the target stimuli were presented to the left ear (right hemisphere), but not when the target stimuli were presented to the right ear (left hemi sphere).

\section{EXPERIMENT 4}

In Experiment 4, we attempted to replicate the results of Ex periment 3 , this time presenting noise to the ear not receiving the auditory target stem.

\section{Method}

The method in Experiment 4 was identical to that in Experiment 3 , except that during each trial in the test phase, a sound stem was presented in one ear, and noise (the same audio file created in Experiment 2) was presented in the opposite ear.

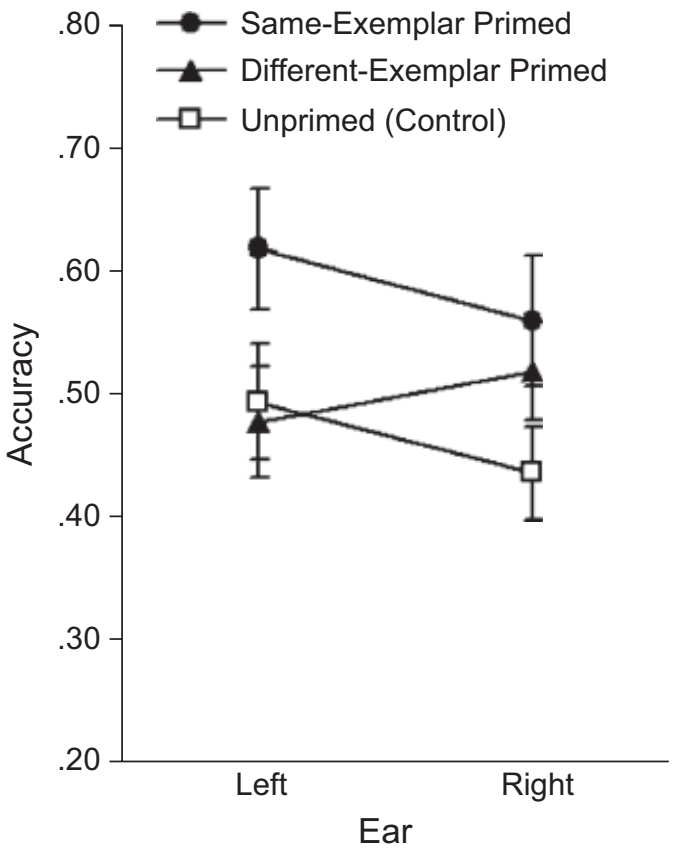

Fig. 3. Mean proportion of naming accuracy in Experiment 3 as a function of prime type and ear of target-stem presentation. Error bars indicate standard errors of the means.

\section{Results and Discussion}

Figure 4 displays the mean proportion of naming accuracy as a function of prime type and ear of target stem presentation. As expected, overall performance was lower than in Experiment 3 because of the noise's masking effect. Again, we obtained a significant main effect of prime type, $F_{1}(2,58)=5.63, M S E=$ $0.067, \eta_{p}{ }^{2}=.16 ; F_{2}(2,46)=9.62, M S E=0.031, \eta_{p}{ }^{2}=.30$. Post hoc analyses revealed significant differences between the same exemplar and control conditions, and between the differ ent exemplar and control conditions. Unlike in the previous experiments, we also observed a significant main effect of ear of target stem presentation; the sound stems administered to the left ear (right hemisphere) were recognized better than the sound stems administered to the right ear (left hemisphere; $M \mathrm{~s}=.45$ and .35 , respectively), $F_{1}(1,29)=5.97, M S E=0.084$, $\eta_{p}{ }^{2}=.17 ; F_{2}(1,23)=15.07, M S E=0.027, \eta_{p}{ }^{2}=.40$.

Planned comparisons demonstrated that the difference be tween the same exemplar and different exemplar conditions $(M \mathrm{~s}=.41$ and .39 , respectively) was not significant when the target stems were presented to the right ear (both $t \mathrm{~s}<1$ ). The difference between these conditions was larger $(M \mathrm{~s}=.53$ and .45) when the target stems were presented to the left ear, al though it was not significant across participants, $t_{1}(29)=1.27$, $p=.213, p_{\text {rep }}=.75, d=0.23$, and reached only marginal significance across items, $t_{2}(29)=1.81, p=.083, p_{\text {rep }}=.97$, $d=0.37$.

It is important to note that overall performance was signifi cantly lower in this experiment $(M=.40)$ than in Experiments 1 


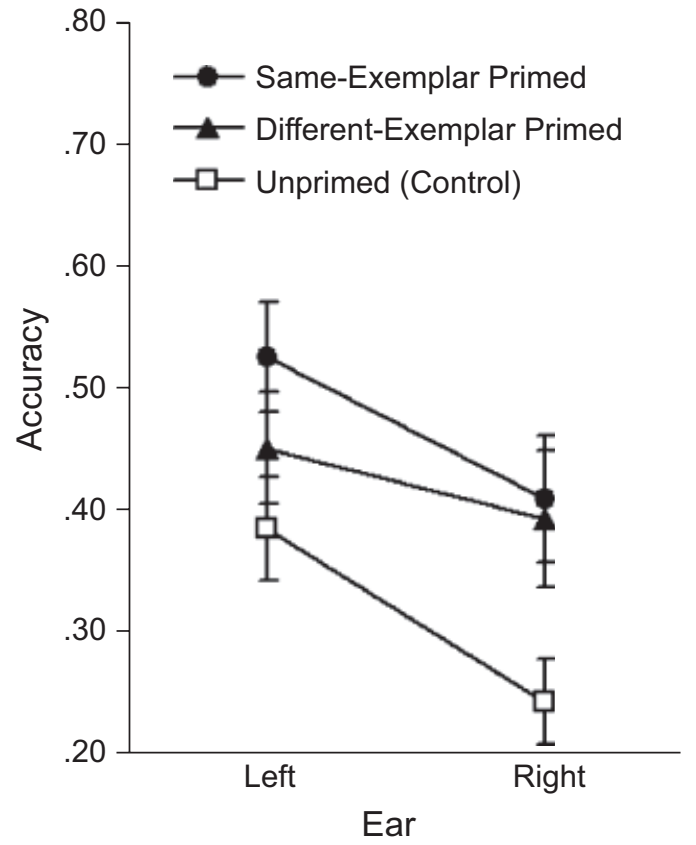

Fig. 4. Mean proportion of naming accuracy in Experiment 4 as a function of prime type and ear of target-stem presentation. Error bars indicate standard errors of the means.

through $3(M \mathrm{~s}=.55, .48$, and .51 , respectively; all $p \mathrm{~s}<.01)$. It is possible that the reduction in overall performance decreased the opportunity to observe specificity and, consequently, effects of hemispheric asymmetry. Nevertheless, although specificity in the right hemisphere was only marginally significant, the pattern of results was consistent with the pattern observed in the pre vious experiments (i.e., greater specificity in the right than in the left hemisphere).

Low overall performance due to demanding conditions (dif ferent study and test tasks, masking noise) may have favored the emergence of the general left ear advantage observed in earlier studies on the identification of environmental sounds. Those studies used dichotic listening tasks, which are presumably more demanding than monaural tasks (Curry, 1967; Knox \& Kimura, 1970).

\section{GENERAL DISCUSSION}

We tested whether specificity effects would be obtained when environmental sounds were presented to the left ear (right hemisphere), but not when they were presented to the right ear (left hemisphere). In four long term priming experiments, we observed specificity effects (an advantage for same exemplar priming relative to different exemplar priming) when target stems were presented to the left ear (right hemisphere), but not when they were presented to the right ear (left hemisphere). This pattern was consistent, emerging when the study and test tasks were the same (Experiments 1 and 2) and when they were different (Experiments 3 and 4), when noise was presented to the opposite ear (Experiments 2 and 4) and when it was not (Ex periments 1 and 3), and when either of two sets of stimuli was used (Experiments 1 and 2 vs. 3 and 4).

The pattern of our data is analogous to the pattern observed in visual object recognition. Given the similarity of our current results on the recognition of acoustic events, our previous results on spoken word recognition (González \& McLennan, 2007), and Marsolek and his colleagues' results (Burgund \& Marsolek, 1997, 2000; Marsolek, 1999, 2004) on visual object and visual word recognition, we suggest that the pattern is not specific to any particular sensory modality, but rather reflects a more general property of the human perceptual processing system. According to the dissociable subsystems theory, an abstract category subsystem operates more effectively in the left than in the right hemisphere and is less sensitive to the specific surface characteristics of stimuli, whereas a specific exemplar subsys tem operates more effectively in the right than in the left hemisphere and is more sensitive to specific stimulus charac teristics. That is, each subsystem is more efficient at a different type of processing: Analytic (features based) processing that does not include specific stimulus characteristics may charac terize the computations of the former subsystem, and holistic (whole based) processing that includes specific stimulus char acteristics may characterize the computations of the latter (Marsolek, 1999).

Some authors have suggested that the widespread existence of specificity effects in several domains implies that specificity has an adaptive value and might be associated with some type of cognitive resource conservation (Schacter, Dobbins, \& Schnyer, 2004). In a continuously changing environment, it is important to categorize the objects and events in one's surroundings in both abstract and specific terms, and this requirement is not exclu sive to any one sensory modality. This dual categorization implies opposing capabilities. Computational reasoning and hemispheric asymmetries suggest that the human brain may perform dual categorization better by means of two dissociable subsystems than by means of a single, undifferentiated system (see Marsolek, 2003). Each of the two theorized parallel neural subsystems, or processing styles, operates more effectively although not exclusively in a different hemisphere and may obey a general processing principle that transcends particular modalities. Several neuroimaging studies of auditory and visual priming have shown reduction of activity in cortical areas in volved in multimodal functions (Buckner, Koutstaal, Schacter, \& Rosen, 2000; Carlesimo et al., 2004; for a review, see Schacter et al., 2004).

In recent years, research has suggested that certain charac teristics of specific processing systems can be integrated into more general principles. For example, the distinction between local and global processing was initially confined to the visual domain. Data suggested a hemispheric specialization: Global (or low spatial frequency) information was preferentially processed 
in the right hemisphere, and local (or high spatial frequency) information was preferentially processed in the left hemisphere (Sanders \& Poeppel, 2007). New data from the auditory domain are consistent with the same general pattern: Relatively slow auditory changes (200 $300 \mathrm{~ms}$ ) are preferentially processed in the right hemisphere, whereas relatively fast changes (25 50 $\mathrm{ms}$ ) are preferentially processed in the left hemisphere (see Boemio, Fromm, Braun, \& Poeppel, 2005). ${ }^{1}$ Given the conver gence of data across modalities, the local global distinction may define a general organizational principle that is compatible with the dissociable subsystems (analytic, holistic) account of lateralization.

The asymmetrical pattern of auditory specificity for word and environmental sound perception should be considered in the more general framework of lateralization of auditory cortex functions. Evidence from behavioral dichotic listening studies and more recent data from positron emission tomography, magnetoencephalography, and functional magnetic resonance imaging research suggest that a parameter model (rapid vs. slow temporal or frequency changes) provides a better account of hemispheric differences than the classical domain (e.g., speech vs. music) model (Tervaniemi \& Hugdahl, 2003). The existence of two subsystems with two different processing styles would fit well with this newer conceptualization of auditory lateralization.

Finally, the possibility that the dissociable subsystems frame work characterizes perceptual and memory processing in multiple modalities suggests directions for future work. For example, behavioral, electrophysiological, and neuroimaging studies could examine potential priming asymmetries in other auditory subdomains, including music perception, voice rec ognition, and pseudoword processing. Also, it would be of in terest to examine asymmetries using synthetic and novel sound stimuli, given the recent hemispheric asymmetries Marsolek and Burgund (2008) observed using novel visual stimuli in a working memory task. Finally, research could extend to the three remaining sensory modalities (touch, taste, and smell). For ex ample, it is an interesting question whether specificity in tactile recognition is greater when objects are handled with the left hand (right hemisphere) than when they are handled with the right hand (left hemisphere).

Acknowledgments This research was supported in part by Grant Consolider Ingenio 2010 from the Ministry of Science and Technology of Spain and by Research Grant R03 DC 007316 from the National Institute on Deafness and Other Communi cation Disorders, National Institutes of Health.

${ }^{1}$ Some authors suggest that lateralization of speech perception may arise as a result of different timescales: Fast auditory changes correspond to segmentaland syllabic-level timing (left hemisphere), and slow changes correspond to prosody- and melody-level timing (right hemisphere).

\section{REFERENCES}

Beeri, M.S., Vakil, E., Adonsky, A., \& Levenkron, S. (2004). The role of the cerebral hemispheres in specific versus abstract priming. Laterality, 9, 313323.

Biederman, L. (1987). Recognition by components: A theory of human image understanding. Psychological Review, 94, 115147.

Boemio, A., Fromm, S., Braun, A., \& Poeppel, D. (2005). Hierarchical and asymmetric temporal sensitivity in human auditory cortices. Nature Neuroscience, 8, 389395.

Buckner, R.L., Koutstaal, W., Schacter, D.L., \& Rosen, B.R. (2000). Functional MRI evidence for a role of frontal and inferior tem poral cortex in amodal components of priming. Brain, 123, 620 640.

Bülthoff, H.H., \& Edelman, S. (1992). Psychophysical support for a two dimensional view interpolation theory of object recogni tion. Proceedings of the National Academy of Sciences, USA, 89, 6064.

Burgund, E.D., \& Marsolek, C.J. (1997). Letter case specific priming in the right cerebral hemisphere with a form specific perceptual identification task. Brain and Cognition, 35, 239258.

Burgund, E.D., \& Marsolek, C.J. (2000). Viewpoint invariant and view point dependent object recognition in dissociable neural sub systems. Psychonomic Bulletin \& Review, 7, 480489.

Carlesimo, G.A., Turriziani, P., Paulesu, E., Gorini, A., Caltagirone, C., Fazio, F., \& Perani, D. (2004). Brain activity during intra and cross modal priming: New empirical data and review of the lit erature. Neuropsychologia, 42, 1424.

Chiu, C. Y.P. (2000). Specificity of auditory implicit and explicit memory: Is perceptual priming for environmental sounds exem plar specific? Memory \& Cognition, 28, 11261139.

Chiu, C. Y.P., \& Schacter, D.L. (1995). Auditory priming for nonverbal information: Implicit and explicit memory for environmental sounds. Consciousness and Cognition, 4, 440458.

Curry, F.K. (1967). A comparison of left handed and right handed subjects on verbal and non verbal dichotic listening tasks. Cor tex, 3, 343352 .

Dobbins, I.G., Schnyer, D.M., Verfaellie, M., \& Schacter, D.L. (2004). Cortical activity reductions during repetition priming can result from rapid response learning. Nature, 428, 316319.

Farah, M.J. (1991). Patterns of co occurrence among the associative agnosias: Implications for visual object representation. Cognitive Neuropsychology, 8, 119.

Farah, M.J. (1992). Is an object an object an object? Cognitive and neuropsychological investigations of domain specificity in visual object recognition. Current Directions in Psychological Science, 1, 164169.

Fecteau, J.H., Enns, J.T., \& Kingstone, A. (2000). Competition in duced visual differences in search. Psychological Science, 11, 386393.

González, J., \& McLennan, C.T. (2007). Hemispheric differences in indexical specificity effects in spoken word recognition. Journal of Experimental Psychology: Human Perception and Performance, $33,410424$.

Hayward, W.G., \& Williams, P. (2000). Viewpoint dependence and object discriminability. Psychological Science, 11, 712.

Hayworth, K.J., \& Biederman, I. (2006). Neural evidence for inter mediate representations in object recognition. Vision Research, 46, 40244031.

Hugdahl, K. (1999). Brain lateralization: Dichotic listening studies. In G. Adelman \& B.H. Smith (Eds.), Elsevier's encyclopedia of neuroscience (2nd ed., pp. 276 279). New York: Elsevier. 
Kimura, D. (1961). Cerebral dominance and the perception of verbal stimuli. Canadian Journal of Psychology, 15, 166171.

Knox, C., \& Kimura, D. (1970). Cerebral processing of nonverbal sounds in boys and girls. Neuropsychologia, 8, 227237.

Koivisto, M. (1995). On functional brain asymmetries in perceptual priming. Brain and Cognition, 29, 3653.

Koutstaal, W., Wagner, A.D., Rotte, M., Maril, A., Buckner, R.L., \& Schacter, D.L. (2001). Perceptual specificity in visual object priming: Functional magnetic resonance imaging evidence for a laterality difference in fusiform cortex. Neuropsychologia, 39, 184199.

Marcell, M.M., Borella, D., Greene, M., Kerr, E., \& Rogers, S. (2000). Confrontation naming of environmental sounds. Journal of Clin ical and Experimental Psychology, 22, 830864.

Marsolek, C.J. (1999). Dissociable neural subsystems underlie ab stract and specific object recognition. Psychological Science, 10, 111118

Marsolek, C.J. (2003). What is priming and why? In J.S. Bowers \& C.J. Marsolek (Eds.), Rethinking implicit memory (pp. 41 64). Oxford, England: Oxford University Press.

Marsolek, C.J. (2004). Abstractionist versus exemplar based theories of visual word priming: A subsystems resolution. The Quarterly Journal of Experimental Psychology: Section A, 57, 12331259.

Marsolek, C.J., \& Burgund, E.D. (2008). Dissociable neural subsys tems underlie visual working memory for abstract categories and specific exemplars. Cognitive, Affective \& Behavioral Neuro science, $8,1724$.

McLennan, C.T., \& Luce, P.A. (2005). Examining the time course of indexical specificity effects in spoken word recognition. Journal of Experimental Psychology: Learning, Memory, and Cognition, 31, 306321.

McLennan, C.T., Luce, P.A., \& Charles Luce, J. (2003). Representa tion of lexical form. Journal of Experimental Psychology: Learn ing, Memory, and Cognition, 29, 539553.
Oldfield, R.C. (1971). The assessment and analysis of handedness: The Edinburgh inventory. Neuropsychologia, 9, 97113.

Pickering, E.C., \& Schweinberger, S.R. (2003). N200, N250r, and N400 event related brain potentials reveal three loci of repetition priming for familiar names. Journal of Experimental Psychology: Learning, Memory, and Cognition, 29, 12981311.

Sanders, L., \& Poeppel, D. (2007). Local and global auditory pro cessing: Behavioral and ERP evidence. Neuropsychologia, 45, 11721186.

Schacter, D.L., \& Church, B.A. (1992). Auditory priming: Implicit and explicit memory for words and voices. Journal of Experimental Psychology: Learning, Memory, and Cognition, 18, 915930.

Schacter, D.L., Dobbins, I.G., \& Schnyer, D.M. (2004). Specificity of priming: A cognitive neuroscience perspective. Nature Reviews Neuroscience, 5, 853862.

Shafiro, V., \& Gygi, B. (2004). How to select stimuli for environmental sound research and where to find them. Behavior Research Methods, Instruments, \& Computers, 36, 590598.

Stuart, G.P., \& Jones, D.M. (1996). From auditory image to auditory percept: Facilitation through common processes? Memory \& Cognition, 24, 296304.

Tarr, M.J., Williams, P., Hayward, W.G., \& Gauthier, I. (1998). Three dimensional object recognition is viewpoint dependent. Nature Neuroscience, 1, 275277.

Tervaniemi, M., \& Hugdahl, K. (2003). Lateralization of auditory cortex functions. Brain Research Reviews, 43, 231246.

Wagemans, T.D., Van Gool, L., \& Lamote, C. (1996). The visual sys tem's measurement of invariants need not itself be invariant. Psychological Science, 7, 232236. 